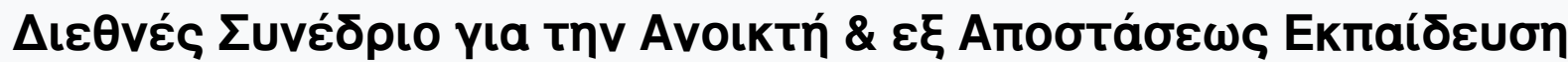

Tóp. 5, Ap. 3B (2009)

Open and Distance Education for Global Collaboration \& Educational Development

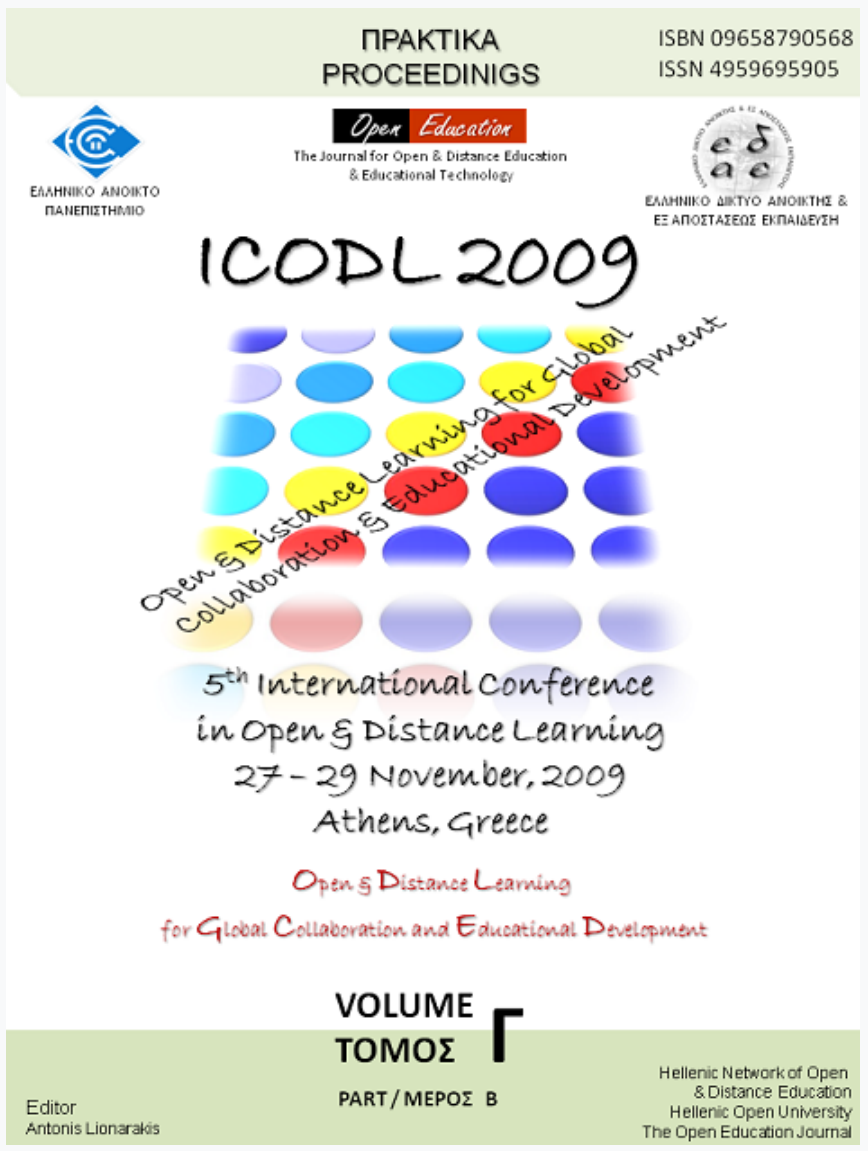

\section{E-learning: The key to open the Learning Doors in European Prisons}

Antonia Maria HARTOFYLAKA, Antonia ARACHOVA, Evangelia MANOUSOU

doi: $10.12681 /$ icodl.519 


\title{
E-learning: The key to open the Learning Doors in European Prisons
}

\section{Antonia Maria \\ HARTOFYLAKA}

Hellenic Open University

thartofylaka@expertones.gr

\author{
Antonia ARACHOVA
}

Evangelia MANOUSOU

Hellenic Open University

gellym@gmail.com

\begin{abstract}
Introduction:
ELBEP (Eliminating Barriers in European Prisons) aims to promote intercultural dialogue and meet the communication needs of prison staff members in the EU countries, regarding many foreign prisoners they encounter in their work environment. Operational definition of "Foreign Prisoners" within the scope of ELBEP covers prisoners who are sentenced and also imprisoned detainees in the trial process. Furthermore, the project is designed to meet the criteria for the Association of Language Testers in Europe (ALTE) A1 level in order to develop products that can be certified and accredited in many European countries. ELBEP focuses on Russian, Polish, Spanish, Greek and Turkish language needs of the EU prison staffs, since foreign prisoners speaking these native languages compose important percentages in European prisons. Overall, the expected impact of teaching beginner's level second languages to European prison staffs, via flexible Open and Distance Learning (ODL) environments, proposes an alternative to solve the communication problems. Concentrating on this objective, ELBEP shall promote intercultural understanding, tolerance for diversity and lead to a suitable environment where rehabilitation and adult education of prisoners are achievable.
\end{abstract}

Goals: The project ELBEP aims to fulfill the following objectives:

(1) Explore the condition of current language barriers between prison staffs and foreign language speaking prisoners in European Prisons,

(2) Determine the level of awareness and perception of prison staffs for the need to learn second languages to be able to communicate with foreign language speaking prisoners throughout European Prisons,

(3) Examine the current competency of prison staffs in second language skills,

(4) Clarify a range of supportive possibilities in European prisons to design ODL environments to provide second language education,

(5) Develop and deliver Second Language e-Learning Portals via ODL media to European Prison staffs,

(6) Evaluate the impact of the program through qualitative and quantitative measurement tools.

The outputs of the project are five online language portals at A1 level (Russian, Polish, Spanish, Greek and Turkish). The impacts envisaged are:

(1) Promote education of guards and other penitentiary authorities within a perspective of lifelong learning

(2) Creating an environment conducive to mutual understanding and learning

(3) Heighten a public awareness concerning particular communication needs of prison staffs and foreign prisoners regarding the ALTE criteria

(4) Improve understanding of the difficulties and cultural backgrounds of foreign prisoners so as to prevent prejudiced attitudes from arising 
(5) Improve the communication within prisons by helping to prevent prejudice and intolerance

(6) Reduce the feelings of discrimination, depression and isolation felt by prisoners

ELBEP aims to solve communication problems of European prison staffs with foreign prisoners in Germany, Belgium and Greece. Prison staffs learning a native language of the foreign prisoners shall initiate steps for mutual understanding and intercultural dialogue. Through their second language education via an e-Learning environment (second language portals: Russian, Polish, Spanish, Greek and Turkish) the staffs shall promote social cohesion as regards both rehabilitation and lives after release.

Target population of ELBEP is the European prison staffs (penitentiary personnel) in Germany, Belgium and Greece for improving their vocational competences. Their A1 level second language education via distance education, shall improve their abilities to communicate with the foreign prisoners in their work environment. Their second language knowledge shall ease communication barriers and pave the way for further rehabilitation and education of the prisoners (indirect target group of ELBEP). Besides increasing the understanding between these two groups, it will be easier to motivate the foreign prisoners for social cohesion and especially for learning language of the host country.

The specific learning need of adults concentrated on via ELBEP is the need for second language learning environments, through which prison staffs can learn basics of the native languages of foreign prisoners that compose highest percentages in their work environments. By increasing their communication abilities and better performing their responsibilities, they will have improved their personal vocational competences, as well. The indirect impact envisaged is greater motivation for rehabilitation and social cohesion on the side of foreign prisoners both before and after release.

3. Some details about the partners' profile and the role of the participant organisation in the project / network

- Anadolu University (AU) is a pioneer institution to solve educational problems in Turkey at a distance since 1982. AU also serves Turkish citizens living in the EU member states. The University has 8 institutes (including research centers), 12 faculties, 7 schools and 4 vocational schools offering face-to-face education. The open education system offers 27 associate and bachelor degree programs. Today, $44 \%$ of the overall on and off campus Turkish higher education students are enrolled at AU' s distance learning system. Teaching materials are designed and prepared with the self-study format. e-Learning portal is composed of e-Practice, e-Book, e-Television, e-Exam, e-Mentoring (a/synchronous) and e-Audio Book. The results of a recent research sponsored by AU Research Development Fund, indicates the need to learn Turkish, in particular, as both mother tongue and second language in seven European countries. According to this need analysis, the consortium aims to focus on meeting second language needs of EU prison staffs.

- "Innowacja" Foundation The main task to be performed by "Innowacja" Foundation in the project is the preparation of polish language E-learning portal. "Innowacja" Foundation will prepare the methodology for teaching prison's staff Polish language using methods of distance learning. As it cooperates closely with Warsaw School of Social and Economic Studies and possess the licence for broadcasting satellite television programs via EDUSAT Television it shall combine experience of those institutions in order to produce relevant TV 
programmes and disseminate the results of the project. It will also deliver produced educational programmes directly to prisons in all target countries via EDUSAT Television.

- LINGUAPOLIS. As a partner with this project will develop a Spanish portal as agreed in the partnership and tailored to the needs of the prisons' staff. Based on our experience with computer-assisted language portals and previous projects we strive to make the tool as learner-oriented and competence-oriented as possible. This goes in lines with the LINGUAPOLIS concept of Distributed Language Learning: Starting from the analysis of the language-learning situation we develop a coherent and high-performing language-learning environment. In this we make a well-founded and sound choice of content materials, tasks, work forms and media. These are used to create a dynamic learning environment with varied learning sources.

- ESTA. The first core activity of will be the planning, operation and technical performance of the training sequences for the target group. These training courses (Train the trainer) will be held in the partner countries and include mediadidactical and media-technological teaching sessions for the audience. The courses will be delivered online, in attendance and as blended learning. All of them having a unique curriculum and will depend on the needs of the people on site. Language of tuition will be English. Second activity of ESTA will be the development and operation of all facilities required for transnational cooperation, like shared workspaces, learning management systems, data-management systems, communication facilities. These facilities will be operated by ESTA for the sake of the project and will be sustained/guaranteed after the project for at least 3 years.

- The Hellenic Open University (HOU) will be part of the 1st group, the one that will produce the e-learning material in teaching Greek as a foreign language for beginners. The roles that the HOU can undertake are the following:

1. Data gathering concerning the percentage of the Greek prisoners, who are located in prisons of the EUs member states that take part in the program, as well as the educational background of program's target group, i.e. the prisons' staff, in order to outline their specific learning needs. The data will be gathered with quantitative as well as qualitative methodological tools. Analysis of the data will provide a clear picture regarding the educational profile of the perspective learners as well as their additional learning needs.

2. Designing and development of an e-learning course in teaching Greek as a foreign language for beginners. This part will be the core of the HOUs contribution to the project. At the end of the program, the University aims to evaluate the effectiveness of the e-learning material. The criteria of evaluation will include a study of the students' performance, as well as the quality of their learning experience.

3. Designing and development of supplemental distance learning course, which would enrich the language distance learning course. The main scope of the course will be the same with that of the main course (language): to facilitate the communication between foreign prisoners and the prisons' staff. A possible subject of the supplemental course could be the respect for diversities (national, religious, sexual, etc).

- EDEN's participation in European Union programmes is focused on comprehensive strategic projects, in quality development, observatory, networking and knowledge base building, further supporting the implementation through 
networking, evaluation and dissemination of results. For such activities, EDEN has developed strategies, supporting tools and templates that are continuously evolving with the years' of experiences of the Association. In the ELBEP project EDEN's main responsibility will be dissemination.

- Participant other than partners in ELBEP: Moscow State University for Economics, Statistics and Informatics (MESI) established in 1932 is one of Russia's leading higher education institutions in the field of economics, statistics and computer science both for Russian nationals and nationals of other countries. In ELBEP, MESI will contribute to the activities of the consortium by its expertise in e-learning, teaching Russian as foreign language as well as instruction of prisoners (experience of MESI Tver branch). MESI will participate in planning of the Language Portals and their design as well as in elaboration of common decision on content framework and methods of teaching/learning. MESI will design Russian Language Portal and elaborate content for it.

In this consortium; Anadolu University; Innowacja Foundation, Hellenic Open University and Linguapolis of the University of Antwerp shall cooperate to prepare their own second language teaching portals in Turkish, Polish Greek and Spanish according to a design of consensus, tailored according to needs of the prison staffs in Europe. Moscow State University of Economics, Statistics and Informatics shall contribute to the consortium on self-funding basis with a Russian teaching portal (RU-EDU). ESTA Bildungswerk shall contribute with its online teaching experiences in the preparation stages of the language portals. Dr. Wolfram Laaser from Fern University shall be advisor for the visual media to be utilised in the language portals, his contribution shall be on subcontracting basis. He is is an Academic Director at the Center for Distance Study Development at Fern University. He has specialized on development of interactive multimedia courseware and web-based training, educational video and TV. ESTA, Linguapolis and HOU will also contribute logistically for the selection of and awareness raising at the penitentiary institutions. They will have roles about preparing the target groups for online language education. EDEN and EADTU as two important European organizations of ODL will contribute to ELBEP at quality assurance and dissemination stages.

4. Immigration in Europe: Immigration towards Western Europe has been escalated in recent years; in the 1990s Western Europe received an average of over 1.650.000 immigrants per year (Solivetti, 2005). Research results indicate that in the 1980s, crime rates for non-nationals were three, four times higher than those for nationals. In Germany, in 2004 the foreign prisoners represented $23.2 \%$ of the prisoner number in total, according to Federal Statistical Office in Germany. In the same year, among 775.802 prisoners in total; 4208 Greek, 10568 Italian, 15870 Former Yugoslavian and 44086 Turkish prisoners were detected in German prisons (Statistisches Bundesamt, Wiesbaden, 2006). Immigrants from Turkey and ex-Yugoslavia constituted 34.1 percent of total population in prisons by the year 2004 (http://www.educationinprison.org). International Centre for Prison Studies at King's College London indicates that in Belgium 42 percent of the prison population were foreign prisoners in 2006 (http://www.kcl.ac.uk/depsta/rel/icps/worldbrief/europe.html). An overview of the foreigners in Belgian prisons indicates; $2.3 \%$ Turkish, $0.9 \%$ Polish, 0.7\% Russian and $0.5 \%$ Spanish prisoners (De Morgen 08/08/06 http://www.npdata.be/Data/Gevangenis/Gevangenen-nationaliteit-c-totaal.htm). The percentage in Greek prisons is almost equal to that in Belgium, 42-44 percent 
of

prisoners

are

foreigners

(http://www.mmo.gr/pdf/library/Greece/grckaimigracija.pdf).

The International Watch on Education in Prison Report titled "Prison Education for Social Inclusion" (Oslo, 2005) indicates that; mobility, cultural and economic globalization, growing number of detainees overseas, and migration towards Europe are considered to be the major challenges in the international context. Growing number of immigrants necessitate a multicultural-identity dimension to be taken into account for education in prison. Furthermore, foreign nationals are overrepresented in prisons and the educational level of foreign prisoners is usually lower than the EU average, stressing the importance of communication in prison as an essential element. Fueled by the general lack of education of foreign prisoners, communication among prison staff and prisoners is a priority which is restricted by a serious language barrier that has to be surmounted.

The respect foreign prisoners seek from the prison authorities ensure their identity and dignity. Prison staffs' ability to communicate in their native languages can help build this respect and support them for education and rehabilitation. The International Watch on Education in Prison, in collaboration with the UNESCO Institute for Education in Hamburg, promotes education of guards and other prison authorities within a perspective of lifelong learning. For breaking the vicious circle of social exclusion, human values such as respect, dignity, tolerance and multicultural citizenship education are foreseen in these programmes (http://www.educationinprison.org). The current project aims to promote intercultural dialogue (in line with the priority of EU announcing the year 2008 as European Year of Intercultural Dialogue) and meet the communication needs of prison staff members in EU countries (limited with Belgium, Germany and Greece in ELBEP for the short term), regarding foreign nationals they encounter in their work environment. This pillar of the multilateral project aims to focus on Russian, Polish, Spanish, Greek and Turkish language needs of EU prisons' staffs, since Russian, Polish, Spanish, Greek and Turkish speaking foreign prisoners compose high percentages in European prisons. The multilateral characteristic of the project shall support the linguistic diversity as targeted in the transversal programme, languages key activity area.

5. The project ELBEP undertakes the communication issues mentioned above, between the EU prison staffs and foreign language speaking prisoners, based on LLP Grundtvig objectives: LLP-Obj-d, GRU-SpObj-2 and priority GRU-4.2.1.4. It has relations with themes covered in the Transversal Programmes of languages and ICT. ELBEP proposes to create an e-learning environment to provide Russian, Polish, Spanish, Greek and Turkish language skills to the prison staffs in EU member countries (Belgium, Germany and Greece). The project is designed to meet the requirements for ALTE A1 standards in order to produce a more reliable and efficient product that can be certified and accredited in many European countries without serious concerns on the credibility issues.

A second language e-Learning portal in the ODL format, addressing the European prison staffs will be developed and delivered to meet the language needs of the direct target population. Objectives of the Project ELBEP are listed as: Promote education of guards and prison (penitentiary) authorities within a perspective of lifelong learning; creating an environment conducive to mutual understanding and learning; improve understanding of the difficulties and cultural backgrounds of foreign prisoners so as to prevent prejudiced attitudes from arising; improve the communication within prisons by helping to prevent prejudice and intolerance; reduce the feelings of discrimination, depression and isolation felt by prisoners; decrease 
possible behavior problems of prisoners; improve services such as consultation, guidance, and health service provided to prisoners; promote and harmonize positive relations between prison institutions and foreign prisoners.

These short and long-term objectives of ELBEP are in conformity with the LLP objective of using lifelong learning for social cohesion and intercultural dialogue. The education foreseen in ELBEP shall also promote access to information on active European citizenship and lead to personal fulfillment of prison staffs through developing their language skills and vocational competences. Thus ELBEP helps provide adult learners with language portals to improve their knowledge and competences, which is sub- programme objective GRU-SpObj-2.

6. The choice of an e-Learning environment as the main delivery method will provide innovative ICT-based content, pedagogy, and service as a lifelong learning opportunity as stressed in Key Activity 3: ICT. The target population will have access to an open and flexible learning environment which overcomes many limitations faced in conventional educational settings, such as time and logistic restrictions of gathering all learners at one place at the same time. Overall, the expected impact of teaching beginner's level second language to European prison staff is solving the communication problem, promoting intercultural understanding, tolerance for diversity and pave the way for a suitable environment where rehabilitation and adult education of prisoners (indirect target group) are achievable.

In order to address the needs explained above, the main pedagogical methodology underlying the project is ODL. The direct target group of this project is guards and prison staffs working in prisons in EU member countries. Indirectly, foreign prisoners detained in different locations/settings in European prisons are targeted with this project. ELBEP shall offer an alternative to solve the communication barrier between prison staffs and foreign prisoners. Here the main need is having basic command of native languages of foreign prisoners (Russian, Polish, Spanish, Greek and Turkish) so that the channels may be open for motivating the prisoners to adaptation, integration and rehabilitation. With this mentality foreign prisoners are the indirect target group to benefit from outcomes of ELBEP. The outputs/products of this project (e-Learning language portals) might be adapted and utilized by other institutions such as Police, Justice Department employees, Border Patrol, Customs and other security service providers in different EU countries for effective and expansive exploitation at European level. Furthermore, EU institutions which interact with foreign language speaking minorities might also be potential beneficiaries of such a project. It is anticipated that ELBEP shall promote an environment conducive to social cohesion through intercultural understanding and tolerance for diversity. Also, the academic outputs and rationale shall be disseminated via conferences, seminars and the portal itself.

Bearing in mind that the portals shall be prepared by three partners in collaboration and sharing good practices of each other; test, implementation and evaluation phases shall be followed by the dissemination phase; has led the consortium to decide on a 24 month duration for the project. A mix of qualitative and quantitative data will be used to create an understanding of both measured impact and process of the project. Qualitative methods will particularly be effective in delving deep into issues of process; a judicious mix of qualitative and quantitative methods are therefore planned to help provide a more comprehensive evaluation of the program. It is believed that the inclusion of qualitative data measurement would also 
help to illuminate other closely related problems that otherwise would not emerge with quantitative measurement tools. On the quantitative part, records of learner achievements and attitude toward the program will be recorded and analysed on the digital platform. Both synchronous and asynchronous measurement tools will assess the effectiveness of the program regarding the ALTE A1 standards to be achieved by adult learners. On the qualitative part, semi-structured in-depth interviews will be utilized to obtain a grounded understanding of issues.

An e-Learning environment shall be developed for teaching second languages (5 languages) via ICT, as a flexible lifelong learning mean. The online character of the programme shall make it open and accessible for all staff interested and offer time and place flexibility for learning. The components of the portals shall be: e-course, ebook, e-practice book, e-television and e-exam.

7. The new mentality

In the past, prison education used to be composed of teaching the language and the customs of the host country only. The mentality was that only the foreign prisoners would learn and accept a new culture. But this has proved to be inadequate concerning their rehabilitation since the prisoners have low educational profiles. Besides, they need their own culture to be able to make sense of their following learning and adaptation experiences. The new mentality behind ELBEP is that prison staffs of European prisons can better motivate the foreign prisoners through having a basic command of the native languages of the latter group. This is a new educational approach supporting the global shift away from monocultural education (7th European Prison Education Association International Conference Proceedings, http://www.epea.org/7thconf/ws-dormer.htm).

The second language portals to be offered via ELBEP to the staffs of penitentiary institutions in three host countries (selected among the partners of the consortium) namely Belgium, Germany and Greece shall have educational contents in conformity with the working environments of the targeted beneficiaries. The educational method of ODL (Open and Distance Learning) is also new in this sense for access to information. In this way, staffs can develop new language skills and use them for improving their vocational competences concerning the communication with the foreign prisoners. Aiming ALTE-A1 standards in teaching Russian, Polish, Spanish, Greek and Turkish to prison staffs, the design of the e-Learning environments shall be tailored according to the needs at the penitentiary institutions for improved relations between staffs and the foreign prisoners. E.g. the scripts for the e-Course and e-Television components shall take issues like intercultural dialogue, tolerance, cultural diversity into consideration. Content shall also reference integration with European values and social cohesion at European level. e-Learning shall provide the opportunity to study with time and location flexibilities. Also ELBEP shall develop communication skills by overcoming the greatest barrier of not speaking any common language with the foreign prisoners for the beginning of the relation. The personnel of the prisons shall be better vested to understand and negotiate with the foreign prisoners and motivate them for first learning the European language spoken in the host country and then for further steps to their rehabilitation and education.

Relevance towards the strategic issues related to the Lifelong Learning Programme 
ELBEP aims overcoming communication problems in prisons between staff and foreign prisoners and help improve interpersonal and intercultural understanding and tolerance. This is the first stage of a social cohesion at Community level and develop social and civic competences of the target groups.

ELBEP is in conformity with the policy of providing cultural and linguistic diversity at the Community level that will be highlighted all through 2008 European Year of Intercultural Dialogue. Reference to less widely taught languages is also important in this framework. Language barriers in the prisons are both reason and outcome of social disorders in the EU countries.

AU, MESI, Linguapolis, HOU and Innowacja Foundation shall work on the contents of the portals separately and meet for monitoring conformity with the unique model decided on, as regards web design, exercises, video clips and evaluation criteria (a/synchronous counselling, exams, certification). The partners shall take the ALTE criteria into consideration in order to prepare the contents at A1 level. This beginner's level linguistic command is limited with daily conversations in environments specified by ALTE.

The language portals prepared by AU, MESI, Innowacja, HOU and Linguapolis shall be finalized and pre-tested for teaching Russian, Polish, Spanish, Greek and Turkish to target groups in the staffs of penitentiary institutions in Belgium, Germany and Greece. The exploitation results shall be disseminated and valorised by EDEN and EADTU.

8. European added value

The expected long-term impacts of the project ELBEP indicate the necessity for activities based on a European consensus for overcoming the intercultural communication barriers, beyond national solutions. The scope of the project is limited with Russian, Polish, Spanish, Greek and Turkish A1 level second language portals for staffs of European prisons in Belgium, Germany and Greece, addressing a limited number of target beneficiaries (determined according to number of a/synchronous advisors of the e-Learning environments). Taking long-term objectives into consideration, the dissemination of the exploitation results shall be important for awareness raising at expanded scale and offering the portals to new target groups in other European countries as well. This shall mean taking steps to improve intercultural understanding at European level, starting with offering alternatives to help overcome linguistic communication barriers that the prison staffs experience with foreign prisoners. The outputs/products of this project, the language portals might be adapted and utilized by other institutions such as Police, Justice Department employees, Border Patrol, Customs and other security service providers in different EU countries for effective and expansive exploitation at European level. Furthermore, other EU institutions which interact with foreign language speaking minorities might also be potential beneficiaries of ELBEP. The academic outputs and rationale shall be disseminated via conferences, seminars and the portal itself, owing to vital contribution of partners EDEN and EADTU. 